\title{
Standbunkt
}

\section{Vom Kampf der Ideen und seinen Folgen}

\author{
Die gegenwärtigen Krisen zeigen schmerzlich auf, wie blind und \\ naiv die Wirtschaftswissenschaft macht. Anstatt dies als bedauer- \\ lichen Betriebsunfall oder unerklärlichen Zufall abzutun, sollten \\ wir uns eingehend mit den Ursachen beschäftigen. Dafür müssen \\ wir auch in die Geschichte dieser Wissenschaft blicken. \\ Von Silja Graupe
}

W ie konnte es passieren, dass niemand die Krise vorhergesehen hat?" Mittlerweile ist diese Frage der Queen legendär. Weniger bekannt ist die Antwort der British Academy: Das Versagen, die Krise zu prognostizieren, sei das wichtigste Beispiel eines Wunschdenkens gepaart mit Hybris. Bei allen Ökonomen, Politikern, Unternehmern und Bankern - habe eine Psychologie des Verleugnens geherrscht. Zwar habe es Experten gegeben, die auf ihren Feldern vor drohenden Problemen gewarnt hätten. Doch „hat die kollektive Vorstellungskraft vieler kluger Menschen, sowohl in diesem Land als auch international, insgesamt versagt, um das Risiko für das Gesamtsystem zu verstehen."

\section{Meinung und Hybris}

Die Frage der Queen verlagert sich damit auf eine tiefere Ebene. Wie entsteht eine solche kollektive Vorstellungskraft? Darauf gibt die British Academy keine Antwort. Sie übersieht damit, dass sich ökonomische Traditionen im letzten Jahrhundert eingehend mit diesem Problem beschäftigt haben. Dies gilt insbesondere für den Neoliberalismus, wenn auch nicht in kritischer Absicht. Leitend für dessen Protagonisten war zunächst die Frage, wie es - in der Sprache der Akteure des neoliberalen Think Tanks The Institute of Economic Affairs (IEA) formuliert - gelingen kann, „Menschen zu überreden, dass nicht nur die marktwirtschaftliche Allokation von Gütern und Dienstleistungen wirtschaftlich ef- fizient und wohlstandssteigernd ist, sondern auch, wesentlich bedeutender, dass die marktwirtschaftliche Allokation allen anderen Methoden des Austauschs überlegen ist." Kurz gesagt, lautet die Antwort, feste Vorstellungen so in den Köpfen der Menschen zu verankern, dass sie Handlungen bereits vor jeglichem Kontakt mit der Realität determinieren.

Friedrich A. Hayek formuliert hierzu das passende Wissenschafts- und Bildungsprogramm. Um ein adäquates „Klima von Meinungen“ zu schaffen, sollten Wissenschaftler über kein konkretes Wissen oder Urteilsvermögen auf einem bestimmten Feld verfügen, sondern lediglich „alle spezifischen Sachverhalte im Licht allgemeiner Ideen beurteilen." Die Macht dieser Ideen wachse dabei „im Verhältnis zu ihrer Allgemeinheit, Abstraktheit und sogar Unklarheit“. Gerade insofern der Wissenschaftler weder originärer Denker noch Experte auf einem bestimmten Feld sei, könne er wirkungsvoll als "gatekeeper of ideas" fungieren. „Es sind die Intellektuellen, die darüber bestimmen, welche Ansichten und Meinungen uns erreichen, welche Fakten wichtig genug sind, um uns mitgeteilt zu werden, und aus welchem Blick sie uns präsentiert werden." Damit entscheiden sie auch, was eine Gesellschaft nicht erkennen kann, weil sie es nicht erkennen soll. Sie prägen, nach Walter Lippmann, deren „Blinde Flecken“.

Die Aufgabe zumindest weiter Teile der Wirtschaftswissenschaft schränkt sich damit ein. Sie haben nur noch wenige intellektuelle Konstruktionen zu vermitteln, die ihren Ursprung im rein Abstrakten haben. Ihren Fortschritt sollen sie allein durch die Anwendung dieser Konstruktionen auf immer mehr Gesellschaftsbereiche definieren, ohne dabei von deren tatsächlichen Problemen auszugehen. Zugleich sollen sie weder eine direkte Verantwortung für die eigene Lebenswelt noch ein Wissen über und aus dieser Welt schulen.

\section{Ökonomisches Denken als Waffe}

Anders gesagt, hat sich die Wirtschaftswissenschaft sowohl zum Ziel als auch zum Mittel der Kriegsführung zu degradieren. In dem Buch „Waging the War of Ideas" vergleicht John Blundell, ehemaliger Generaldirektor des IEA, neoliberale Think Tanks mit einer Artillerie, die unablässig ihre Granaten (Ideen) auch auf die Wissenschaft abfeuere. Manche würden ihr Ziel (die Intellektuellen) erreichen, andere würden es verfehlen. Aber niemals übernähmen die Think Tanks selbst die Rolle der Infanterie, sich in kurzfristigem, persönlichem Ringen mit dem Feind aufzureiben. Vielmehr ebnete ihr Bombardement den Weg für andere, um diese Arbeit zu erledigen.

Wir sollten diese, dem Ökonomen und seiner Wissenschaft zugedachten Rolle im Kampf der Ideen intensiv reflektieren. Ansonsten drohen wir, unsere kollektive Blindheit weiterhin als Zufall (oder Naturereignis) und deren reale Folgen allenfalls als Kollateralschaden wahrzunehmen. Wie können wir, gerade in der Bildung, das ökonomische Denken aus seiner Funktion als Waffe befreien?

\section{Anmerkung}

Der Text zitiert überwiegend aus Lippmann, Walter (1922): Public Opinion und Hayek, Friedrich A. (1949): The Intellectuals and Socialism.

\section{AUTORIN + KONTAKT}

Silja Graupe ist Professorin für Ökonomie und Philosophie an der Cusanus Hochschule i. G. in Bernkastel-Kues und Mitglied des Präsidiums dieser Hochschule.

Weitere Informationen unter www.silja-graupe.de. 